\title{
Panorama de la economía social en Chile: la brecha entre definiciones formales y sustantivas ${ }^{1}$
}

\author{
Eduardo Letelier Araya ${ }^{2}$, Julien Vanhulst ${ }^{3}$, Beatriz Cid Aguayo ${ }^{4}$ y Raúl González Meyer ${ }^{5}$
}

Recibido: 8 de noviembre de 2018 / Aceptado: 2 de julio de 2019

Resumen. El presente artículo busca dimensionar y caracterizar el sector de la economía social en Chile al año 2015, adaptando la tipología propuesta por EESC/CIRIEC para Europa. A partir de la sistematización de datos cuantitativos primarios levantados para el estudio, se plantea una visión panorámica comparable con otros países que usan la tipología de EESC/CIRIEC y complementaria a los estudios realizados sobre el subsector no mercantil de la economía social en Chile. De acuerdo a los resultados obtenidos en el estudio, en el año 2015 la economía social en Chile empleó a 313.591 trabajadores remunerados y generó ingresos monetarios por US\$8.963 millones. Estas cifras son equivalentes al 3,8 por ciento de la ocupación y del 3,7 por ciento del PIB de Chile, respectivamente, situando al país por debajo del promedio de la Unión Europea y por encima de países de ingreso per cápita comparables como Grecia o Polonia. No obstante, debido a la alta tasa de organizaciones y empresas informales estos valores podrían estar subestimados en un rango de 64 a 83 por ciento, respectivamente. Más aún, antecedentes relativos al empleo voluntario o no remunerado en el subsector no mercantil, apuntarían hacia la duplicación del número de trabajadores que participan en el sector de la economía social en Chile. El artículo concluye con una reflexión acerca de la tensión entre definiciones formales y substantivas de la economía social y las dificultades de definir criterios de demarcación sin ambigüedades, en atención a distintas situaciones que se presentaron en el proceso de levantamiento de información para el estudio.

Palabras clave: Economía solidaria; Cooperativas; Tercer sector; Sociedad civil; Empresas sociales.

Claves Econlit: E01; J54; L30; L31.

1 Este artículo ha sido elaborado en el marco del proyecto de investigación "Cartografías de Economías Heterogéneas", financiado por el Fondo Nacional de Desarrollo de la Ciencia y Tecnología (Fondecyt $\mathrm{N}^{\circ} 1160186$ ). Agradecemos la colaboración de Alejandra Duarte y María Alicia Campos en el levantamiento y tratamiento de los datos primarios.

2 Universidad Católica del Maule, Chile

Dirección de correo electrónico: eletelier@ucm.cl

3 Universidad Católica del Maule, Chile

Dirección de correo electrónico: julien@ucm.cl

4 Universidad de Concepción, Chile

Dirección de correo electrónico: beatrizcid@udec.cl

5 Universidad Academia de Humanismo Cristiano, Chile

Dirección de correo electrónico: rgonzalezm@docentes.academia.cl 
[en] Social economy landscape in Chile: the gap between formal and substantive definition

\begin{abstract}
This article seeks to dimension and characterize the social economy sector in Chile by 2015, adapting the typology proposed by EESC / CIRIEC for Europe. Based on the systematization of primary quantitative data collected for the study, a panoramic vision is proposed that is comparable with other countries using the EESC / CIRIEC typology. In the same way, this vision complements studies carried out on the non-commercial subsector of the social economy in Chile. According to the results obtained in the study, in 2015 the social economy employed 313,591 paid workers in Chile and it generated US \$ 8,963 million of monetary incomes. These figures are equivalent to 3.8 percent of employment and 3.7 percent of Chile's GDP, respectively, placing the country below the average of the European Union and above countries of comparable per capita income such as Greece or Poland. However, due to the high rate of informal organizations and companies these values could be underestimated in a range of 64 to 83 percent, respectively. Moreover, background information on voluntary or unpaid employment in the non-commercial subsector would point to doubling of the number of workers participating in the social economy sector in Chile. The article concludes with a reflection on the tension between formal and substantive definitions of the social economy and the difficulties of defining unambiguous demarcation criteria, in response to different situations that arose in the process of gathering information for the study.
\end{abstract}

Keywords: Solidarity economy; Cooperatives; Third sector; Civil society; Social enterprises.

Sumario. 1. Introducción. 2. Marco teórico. 3. Marco metodológico. 4. Resultados. 5. Discusión. 6. Conclusiones. 7. Referencias bibliográficas.

Cómo citar: Letelier Araya, E., Vanhulst, J., Cid Aguayo, B. y González Meyer, R. (2019) Panorama de la economía social en Chile: la brecha entre definiciones formales y sustantivas. REVESCO. Revista de Estudios Cooperativos, Tercer Cuatrimestre, $\mathrm{N}^{\circ}$ 132, pp. 144-168. DOI: 10.5209/REVE.65484.

\title{
1. Introducción
}

En los últimos 50 años, se han multiplicado los diagnósticos y evidencias de una "crisis multidimensional" (i.e. socioeconómica y ecológica), o "crisis de civilización" (Brand, 2015; Escobar, 2011; Leff, 2014). Estos antecedentes plantean la necesidad urgente de un nuevo "modelo cultural" que apuntaría a cambiar los modos de consumo, las formas de organización de la producción y las relaciones sociales, y proponer nuevos indicadores y métricas para orientar las trayectorias de desarrollo (Costanza, R., Alperovitz, G., Daly, H., Farley, J., Franco, C., Jackson, T.\& Víctor, P., 2013; Harvey, 2014) y crear mundos que sean social y ambientalmente justos (Gibson-Graham, Cameron \& Healy, 2013). En América Latina, frente a la instalación de políticas económicas de tipo neoliberal en el último cuarto del siglo XX, algunas propuestas "heterodoxas" han reconsiderado prácticas y experiencias económicas no-capitalistas, a fin de construir nuevos imaginarios políticos más allá del mercado y del Estado (Escobar, 1992, 1995; González-Meyer y Richards, 2012), revalorizando expresiones históricas como el mutualismo, sindicalismo, cooperativismo y empresas autogestionadas de trabajadores; y también iniciativas más contemporáneas como el comercio justo, el turismo comunitario y el consumo responsable. Comúnmente, estas diversas expresiones económicas se han agrupado bajo la denominación de "economía social y solidaria" o sector solidario de la economía (Coraggio, J.L., 
Arancibia, M.I. y Deux, M.V. 2010; Razeto, 1994), abriendo paso a procesos de reconocimiento constitucional y/o formulación de políticas públicas de fomento (Guerra, 2010).

En Chile, el fomento de este tipo de empresas desde políticas públicas tuvo un breve desarrollo en los inicios de la década de 1990, después del restablecimiento de la democracia y bajo el prisma de la "superación de la pobreza" (GonzálezMeyer \& Donovan, 2005; Concertación de Partidos por la Democracia, 1989). Sin embargo, rápidamente, este impulso fue anulado por la hegemonía neoliberal, por la cultura individualista que se entroniza en el modelo de desarrollo chileno y por la débil incidencia pública del sector solidario de la economía (de la Maza, 2002, PNUD, 2015). El interés renovado por la economía social surge después del año 2010, de la mano de la instalación, al centro de los debates políticos, de los tópicos de la inclusión, equidad y sustentabilidad, promovidos tanto local como globalmente por diversos movimientos sociales (Bajoit y Vanhulst, 2016; Stoessel, 2014; Pleyers \& Capitaine, 2016). Destaca en particular la creación de la División de Asociatividad y Economía Social (DAES) al interior del Ministerio de Economía, Fomento y Turismo; y el diseño e implementación de una política de fomento la economía social en el gobierno de la presidenta Bachelet (2014-2018), después de casi dos décadas de ausencia de la economía social en el espacio público (DAES, 2015). No obstante, esta implementación no estuvo exenta de debate en relación a qué tipo de experiencias, iniciativas o empresas debían ser reconocidas como parte de la economía social y ser sujeto y objeto de políticas públicas (CONFECOOP, 2017). A nivel gubernamental, un criterio formal fue usado para reconocer como parte de la economía social a un conjunto de figuras legales que ya se encontraban bajo la supervigilancia del Ministerio de Economía, Fomento y Turismo, como era el caso de las cooperativas, las asociaciones gremiales y las asociaciones de consumidores. A éstas se añadieron las empresas de Comercio Justo y las denominadas "Empresas B", cuyas expresiones legales comprenden desde sociedades mercantiles hasta fundaciones privadas sin fines de lucro, pero cuyas identidades y regulaciones están dadas por sistemas de certificación privados. Sin embargo, otras expresiones relevantes de la economía social como la de las comunidades y asociaciones indígenas, organizaciones comunitarias, corporaciones, fundaciones y sindicatos, quedaron fuera de este marco de política pública (Radrigán y Barría, 2005; González-Meyer, R., Vanhulst, J., Letelier, E. Cid, B. y de Armas, T., 2016). Por consiguiente, a la fecha sigue abierta la cuestión del criterio de delimitación de la economía social con miras a la formulación de políticas públicas.

El presente artículo busca contribuir a esta discusión, proponiendo una visión panorámica de la economía social en Chile, a partir de la adaptación de la definición propuesta por EESC/CIRIEC (2012) para caracterizar a este sector en el contexto europeo. Para ello, el artículo contiene las siguientes secciones: un marco teórico que discute la noción de pluralidad económica y de economía social, identificando criterios para delimitar el sector de la economía social y sus distintas expresiones. Sigue una sección sobre el diseño metodológico (fuentes de información, método y criterios utilizados) y una sección con la presentación de los resultados obtenidos. La sección siguiente abre una discusión de los resultados, a la luz de hallazgos encontrados en este ejercicio de delimitación y dimensionamiento 
de la economía social en Chile. Finalmente se presentan las principales conclusiones y cuestiones abiertas por la presente investigación.

\section{Marco teórico}

\subsection{Una comprensión plural de la economía}

El capitalismo ha venido a constituirse como una meta-narrativa de alcance global y ha penetrado prácticamente todas las esferas de la vida (Boltanski \& Chiapello, 1999; Dardot \& Laval, 2009). Ha sido acompañado de una visión de la economía y del mercado como una máquina autorregulada, así como del crecimiento económico como indicador de bienestar de toda sociedad (Gibson-Graham et al., 2013). Sin embargo, esta perspectiva ignora los aportes de las investigaciones en economía antropológica (Mauss 1925; Sahlins 1972) que mostraron la existencia de mercados precapitalistas; y también los análisis de economía comprensiva (Polanyi, 1944; Granovetter, 1985; Razeto, 1994) o de sociología económica (i.a.: Bourdieu, 2000; Weber, 1922) que complejizan la economía neoclásica y cuestionan el imaginario dominante de una economía estable que se autorreproduce fuera de otros tipos de relaciones sociales y bajo una racionalidad única y universal y no como procesos de tipo institucional. En particular, bajo un enfoque ontológico, epistemológico y metodológico post estructuralista, Gibson-Graham (2006) exploran la realidad caleidoscópica de la esfera económica entendida como un ensamblaje de diversas prácticas, valores, saberes y actantes interrelacionados e interdependientes. De este modo, reconocen y analizan distintas expresiones económicas que incluyen, pero no se limitan, al capitalismo; y muestran que las formas económicas más o menos alternativas no necesariamente son locales, marginales o remanentes del pasado destinados a desaparecer. Así, cuestionan el universalismo del discurso del desarrollo y de la ontología económica dominante; y simultáneamente, abren espacios teóricos y prácticos que permiten reconocer experiencias y racionalidades económicas postcapitalistas y sustentables (GibsonGraham et al., 2013; Healy, 2009). Estas diversas expresiones económicas responden a demandas y necesidades en las afueras del Estado como del mercado (de Nanteuil \& Laville, s/f).

En América Latina, las propias insuficiencias y derivas de los procesos de desarrollo han posibilitado una teorización sobre una economía popular que condensa diversas estrategias de subsistencia (o de subversión) que diversos grupos sociales mantienen y que corresponden en parte, a procesos de reafirmación de la autonomía cultural de pueblos y nacionalidades; y en parte, a nichos de generación de empleo e ingresos en el contexto de economías modernas (Coraggio et al., 2010; Coraggio, 1994, 1998). De este modo se revalorizan prácticas pre-capitalistas que dejan de ser consideradas como expresiones de sociedades atrasadas o tradicionales por superar. En la perspectiva de Razeto (1994), el reconocimiento de tales experiencias, iniciativas o emprendimientos de la economía popular alimentó la teorización sobre factores de producción más allá del capital y del trabajo, destacando la noción de "factor C" o factor comunitario y el carácter central que puede asumir en la constitución y gestión de experiencias, iniciativas o 
emprendimientos orientadas al bien común. Del mismo modo, ha permitido articular y poner en perspectivas relaciones económicas de tipo solidario (i.e. cooperación, comensalidad, donación y reciprocidad) como características de este tipo de emprendimientos Finalmente, tanto la centralidad del trabajo y del factor comunitario como el predominio de relaciones económicas solidarias ha inspirado el reconocimiento analítico de un sector o mercado solidario, cuya racionalidad especial lo diferenciaría del sector o mercado de intercambio, tematizado por la economía neoclásica, y de un sector o mercado regulado, tematizado por la economía fiscal o keynesiana, abriendo paso al reconocimiento de una economía definida como "metautilitarista" (Gaiger, 2017). Desde esta perspectiva, la contrapartida histórica y concreta de esta diferenciación analítica de sectores o mercados especiales, lo constituiría el "mercado determinado", que puede así ser desnaturalizado y comprendido como una construcción social y cuyo entramado de tipos empresas y flujos expresarían la condición real de funcionamiento de la economía.

Siguiendo el enfoque de Razeto (1994), la dimensión jurídica o formal de este tipo de empresas u organizaciones económicas, correspondería a un aspecto parcial de su reconocimiento como parte del sector solidario de la economía, cuyo correlato sustantivo estaría dado por los objetivos económicos realmente presentes a nivel de cada una de ellas y que se expresarían en sus diversas lógicas operacionales (por ej.: fijación de remuneraciones, distribución de excedentes, participación en toma de decisiones, equidad de género, etc.). Dicho de otro modo, el carácter formal podría venir a refrendar o bien a encubrir el carácter sustantivo de un emprendimiento en tanto cooperativa, mutual, fundación, organización comunitaria y otras formas legales no orientadas por la búsqueda del lucro. Por consiguiente, constituiría una guía o criterio inicial para la identificación de este tipo de emprendimientos, sin constituir un aspecto definitorio. En esta dirección, algunos autores han propuesto criterios jurídicos para delimitar, en el marco institucional chileno, las entidades que corresponden a las categorías de tercer sector (Vásquez y Juppet, 2013), empresa social (Alcalde, 2016) u organización privada sin fines de lucro (Alcalde, 2015).

Desde la perspectiva de Coraggio et al. (2010), la definición de sector de la economía social y solidaria comprendería tanto la noción de volver a incrustar la economía en lo social como la noción del establecimiento de relaciones económicas de tipo solidaria entre las empresas o unidades económicas. De este modo, plantean una definición de sector de la economía social y solidaria como compuesto tanto de empresas de la economía popular como de la economía estatal y de la economía capitalista. Esto implicaría reconocer que no todas las empresas o unidades domésticas que componen la economía popular establecen relaciones solidarias ni deben ser reconocidas como parte de la economía social y solidaria. Y también que algunas empresas del Estado y algunas empresas capitalistas podrían ser consideradas parte de la economía social y solidaria, en atención al tipo de relaciones económicas que establecen. Para algunos autores, esta última posibilidad abre la necesidad de distinguir entre "sector" y "campo" de la economía social y solidaria, que además de empresas abarcaría a entidades de promoción e incluso a agencias públicas (Gide, 1930). Finalmente, otros autores plantean la necesidad de distinguir el sector solidario de la economía de una economía social y solidaria 
como tal, evaluable en términos de niveles de integración económica, capacidad expresiva e influencia política y cultural (González-Meyer, 2018).

\subsection{Elementos definitorios de la economía social}

A partir del reconocimiento de empresas u organizaciones económicas que van más allá de lógicas capitalistas o estatales, diversos estudios han intentado generar criterios de delimitación para clasificarlas como parte de un sector de empresas diferenciado, con miras a la formulación de políticas públicas de fomento específicas. Destaca el desarrollo del concepto de economía social en Europa, que si bien tiene una trayectoria histórica que arranca en el siglo XIX, no es sino hasta la década de los noventa del siglo pasado que ha sido reconocida por distintos órganos de la Unión Europea, adoptando resoluciones en orden a identificarla, caracterizarla y promoverla (EESC/CIRIEC, 2016; Chaves Ávila et al., 2013).

En esta dirección, a contar del 2011 la Comisión Europea ha definido recomendaciones para la elaboración de cuentas satélite de empresas de economía social a nivel de los estados miembros, las que han venido siendo adoptadas por diversos países del bloque. Para atender a este esfuerzo, en el año 2012 el Centro Internacional de Investigación e Información sobre la Economía Pública, Social y Cooperativa (CIRIEC) formuló una definición de economía social que recogía las definiciones propuestas por los propios actores y buscaba armonizarlas con el Sistema Europeo de Cuentas Nacionales y Regionales, en su versión 2010 (i.e. ESA 2010). De este modo, la economía social fue definida como "el conjunto de empresas privadas, formalmente organizadas, con autonomía de decisión y libertad de membresía, creadas para cumplir las necesidades de sus miembros a través del mercado mediante la producción de bienes y provisión de servicios, seguros y financiamiento, donde la toma de decisiones y cualquier distribución de ganancias y excedentes entre los miembros no está directamente vinculada al capital o a pagos aportados por cada miembro, cada uno de los cuales tiene un voto, o ante todo evento son decididos a través de un proceso participativo y democrático. La economía social también incluye entidades privadas, formalmente organizadas con autonomía de decisión y libertad de membresía que produce servicios no mercantiles para los hogares y cuyos excedentes, si hay alguno, no pueden ser apropiados por los agentes económicos que las crean, controlan y financian" (EESC/CIRIEC, 2012: 22). Esta definición de economía social reconoce la existencia de algunas empresas u organizaciones que no cumplen con la totalidad de los criterios propuestos en la definición de economía social propuesta por CIRIEC, como es el caso de organizaciones no lucrativas que son productoras de servicios no comerciales para hogares, aun cuando no posean una estructura democrática, en la medida que esto permite incluir en la economía social la prominente acción de las denominadas Organizaciones del Tercer Sector, que producen bienes sociales o meritorios de incuestionable utilidad social.

De acuerdo a la definición la EESC/CIRIEC (2012), la economía social estaría compuesta de dos principales subsectores: a) el subsector empresarial o mercantil y b) el subsector de productores no mercantiles. En particular, las empresas del sector mercantil de la economía social comparten el hecho de ser creadas para satisfacer las necesidades de sus miembros sobre la base del principio de ayuda mutua, 
siendo mutuales, cooperativas y empresas sociales las principales exponentes. Del mismo modo, todas orientan su producción hacia la venta en el mercado a un precio económicamente significativo. Finalmente, mientras pueden distribuir algún excedente $^{6}$ entre sus miembros, este no es proporcional al capital o a las cuotas aportadas por ellos sino de acuerdo a las transacciones de los socios con la respectiva empresa u organización.

Sin perjuicio de lo anterior, es relevante destacar que la definición de sector mercantil de EESC/CIRIEC (2012) comprende a organizaciones no mercantiles que proveen servicios financieros y no financieros a empresas de la economía social y también a sociedades comerciales constituidas por entidades de economía social. Es decir, reconoce tanto la existencia de agencias de fomento, intermediarios financieros sin fines de lucro, etc. Y también la existencia de empresas de tipo lucrativo pero que actúan como subsidiarias de empresas sociales en mercados determinados ${ }^{7}$. Por su parte, las empresas del sector no mercantil de la economía social se caracterizan por orientar la mayor parte de su producción de bienes o de su provisión de servicios, libre de costos o a un precio que no es económicamente significativo. Estas organizaciones son privadas, formalmente constituidas, con autonomía de decisión y libertad de membresía que producen bienes no comerciales para hogares y cuyos excedentes, si existen, no pueden ser apropiados por los agentes económicos que las crean, controlan o financian. Sus principales recursos, aparte de algunas ventas ocasionales, provienen de contribuciones voluntarias en dinero o especie desde los hogares, en sus capacidades como consumidores, desde pagos o transferencias realizadas por el gobierno o de rentas de propiedades. Este segmento incluye fundaciones, asociaciones no mercantiles de interés mutuo o de interés general, asociaciones gremiales, organizaciones de asistencia social, sindicatos, asociaciones de consumidores, partidos políticos, iglesias o sociedades religiosas y clubes deportivos, sociales, culturales o recreacionales. Aquellas que no poseen personalidad jurídica son consideradas en el sector de hogares, aunque suelen ser poco numerosas.

Si bien esta definición ha sido desarrollada y aplicada en el contexto europeo, podemos observar semejanzas con definiciones provenientes de observatorios latinoamericanos de la economía social y solidaria. De este modo, más allá del debate teórico sobre la economía social, tanto en Europa como en América Latina las definiciones operativas de instituciones públicas, sectoriales y/o académicas no divergen mucho de la propuesta de EESC/CIRIEC (2012) adoptada en distintas cuentas satélites de países europeos. Por ejemplo, la definición de la economía social del Observatorio Iberoamericano del Empleo y la Economía Social $(\mathrm{OIBESCOOP})^{8}$ plantea como núcleo identitario común el carácter libre,

6 El concepto de excedente no es lo mismo que ganancia o beneficio. En la generación de ganancias o beneficios, la preminencia la tienen quienes aportaron el capital, una vez pagados los distintos costos de producción y que incluyen al trabajo. En la generación de excedente la preminencia la tienen los trabajadores que participan de la creación de valor. El financiamiento o dinero sólo recibe el interés por su uso o alguna otra compensación limitada.

7 De este modo, el concepto de sector de la economía social y solidaria se acerca a la noción de "campo", planteada por Gide (1930).

8 Cabe destacar que el CIRIEC colabora al Observatorio Iberoamericano de Economía Social y Cooperativa, del mismo modo que el Instituto Universitario de Economía Social y Cooperativa IUDESCOOP de la Universitat 
voluntario, participativo y habitualmente democrático de las entidades que conforman el sector, siendo creadas desde la sociedad civil para satisfacer y resolver las necesidades de los individuos, hogares o familias, o para dar cobertura a sus empresas y organizaciones, antes que para retribuir a inversores o empresas capitalistas. (Monzón y Radrigán, 2009).

No obstante, el mismo hecho de que en la definición de economía social planteada por EESC/CIRIEC (2012) se establezcan excepciones en el cumplimiento de algunos criterios definitorios de economía social (por ej. control democrático), a favor de la inclusión de subsectores relevantes de empresas sociales, permite plantear la necesidad de que estas salvedades puedan establecerse a partir de la evaluación de cada realidad nacional.

\section{Marco metodológico}

\subsection{Delimitación del sector de la economía social}

A partir de la adaptación de figuras legales vigentes en Chile a la definición de economía social propuesta por CIRIEC (EESC-CIRIEC, 2012), se identificaron estudios y bases de datos que pudieran permitir delimitar el sector de la economía social en Chile, desde la perspectiva de la cantidad de organizaciones que lo conformarían. En particular, destacan los catastros ejecutados en los años 2004 y 2015 bajo los auspicios de la Universidad John Hopkins y que emplearon la definición de "sector sin fines de lucro" y "organizaciones de la sociedad civil", respectivamente, para identificar y caracterizar gran parte del subsector no mercantil de la economía social (Irarrázaval et al., 2006; PUC, 2016). Estos estudios utilizan una definición de formalidad que es más amplia que la simple existencia de personalidad jurídica, como es el caso de centros de alumnos y centros de padres y apoderados, que cuentan con estatutos y son identificados en un directorio del Ministerio de Educación, sin que esto implique que se hayan conformado legalmente. Desde el punto de vista de las cuentas satélites europeas (i.e. ESA 2010), estas agrupaciones quedan subsumidas en el sector no mercantil bajo la denominación de "hogares" y que comprende a organizaciones sin personalidad jurídica que atienden a hogares. Por otra parte, desde el punto de vista de la delimitación del sector no mercantil de la economía social propuesta por ESSC-CIRIEC (2012), los estudios de Irarrázaval et al. (2006) y PUC (2016), excluyeron tres expresiones relevantes en Chile?:

Asociaciones indígenas: excluidas en atención a la posibilidad legal de que las utilidades o excedentes de estas asociaciones pudieran ser distribuidos entre sus socios o integrantes.

de València (España), la Fundación Iberoamericana de la Economía Social (FUNDIBES) y la Universidad de Chile.

9 También se excluyeron mutuales y cajas de compensación de asignación familiar, constituidas por empleadores como corporaciones privadas sin fines de lucro sobre la base de leyes especiales; clubes deportivos profesionales conformados como sociedades anónimas deportivas; corporaciones privadas sin fines de lucro constituidas por municipalidades y universidades estatales. Sin embargo, estas exclusiones son concordantes con la definición de economía social propuesta por EESC-CIRIEC (2012). 
- Asociaciones de culto religioso: excluidas por la inexistencia de un registro sistemático que permita asegurar la exhaustividad en la construcción de la base de datos. No obstante, incluir otros tipos de organizaciones de inspiración religiosa como universidades y organizaciones de servicio social, entre otras.

- Asociaciones de propietarios: excluidas en virtud de que la copropiedad de un inmueble conlleva responsabilidades ineludibles y que, por tanto, estas asociaciones no serían plenamente voluntarias.

En consecuencia, con el fin de homologar la definición de economía social propuesta por ESSC-CIRIEC (2012) con los catastros levantados por Irarrázaval et al. (2006) y PUC (2016), fue necesario levantar información catastral adicional sobre estas tres expresiones excluidas del subsector no mercantil. Adicionalmente, de la revisión de los catastros realizados en ambos estudios pudo detectarse un cambio de criterio de clasificación que en el año 2004 llevó a excluir a las denominadas "universidades privadas", las que luego fueron incluidas en el estudio del año 2015. Por consiguiente, a fin de conservar la homogeneidad de la información se consideró relevante adicionar a las universidades privadas al registro de organizaciones del sector no mercantil para el año $2004\left({ }^{10}\right)$.

Por otra parte, la definición de economía social de ESSC/CIRIEC (2012) comprende un subsector mercantil conformado en lo fundamental por cooperativas, asociaciones, fundaciones y corporaciones privadas sin fines de lucro, que atienden a corporaciones financieras y no financieras de la economía social, además de las sociedades comerciales con fines de lucro conformadas como subsidiarias de organizaciones de economía social (Meira, 2019). Consecuentemente, para dar cuenta de este subsector de la economía social fue necesario recurrir a catastros y estudios complementarios. La Tabla 1 sintetiza las fuentes de información utilizadas para cada subsector.

Tabla. 1. Fuente de información utilizadas para dimensionar y caracterizar el sector de economía social en Chile

\begin{tabular}{|l|l|l|l|}
\hline $\begin{array}{l}\text { Sector } \\
\text { Institucional } \\
\text { ESA 2010 }\end{array}$ & Entidad de economía social & Fuente de información \\
\hline
\end{tabular}

10 De acuerdo al análisis de los estados financieros de las universidades privadas compilados por el Ministerio de Educación, este cambio metodológico explicaría casi dos tercios del incremento en el gasto de las organizaciones de la sociedad civil reportado entre 2004 y 2015. 


\begin{tabular}{|c|c|c|c|}
\hline \multirow{2}{*}{ 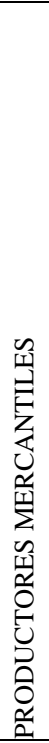 } & $\begin{array}{l}\text { Corporaciones } \\
\text { no financieras }\end{array}$ & $\begin{array}{l}\text { Cooperativas y sus federaciones y } \\
\text { confederaciones (excepto las de ahorro y } \\
\text { crédito y de préstamo) } \\
\text { Asociaciones, fundaciones y } \\
\text { corporaciones privadas sin fines de lucro } \\
\text { que proveen servicios no financieros a } \\
\text { corporaciones no financieras de la } \\
\text { economía social (i.e. asesoría, } \\
\text { capacitación, etc.) } \\
\text { Sociedades comerciales constituidas por } \\
\text { entidades de economía social }\end{array}$ & $\begin{array}{l}\text { Registro público de } \\
\text { cooperativas } \\
\text { Nómina de personas jurídicas y } \\
\text { de empresas personas jurídicas } \\
\text { del Servicio de Impuestos } \\
\text { Internos } \\
\text { Directorio de Coordinadora } \\
\text { Nacional de Comercio Justo } \\
\text { Directorio de Asociación } \\
\text { Chilena por el Comercio Justo }\end{array}$ \\
\hline & $\begin{array}{l}\text { Corporaciones } \\
\text { financieras }\end{array}$ & $\begin{array}{l}\text { Asociaciones, } \quad \text { fundaciones } \\
\text { corporaciones privadas sin fines de lucro } \\
\text { que proveen servicios financieros a } \\
\text { corporaciones no financieras de la } \\
\text { economía social (i.e. microcrédito, fondos } \\
\text { privados de inversión social, etc.) } \\
\text { Cooperativas de ahorro y crédito y } \\
\text { cooperativas de préstamo }\end{array}$ & $\begin{array}{l}\text { Registro público de } \\
\text { cooperativas } \\
\text { Nómina de personas jurídicas y } \\
\text { de empresas personas jurídicas } \\
\text { del Servicio de Impuestos } \\
\text { Internos }\end{array}$ \\
\hline & $\begin{array}{l}\text { Hogares } \\
\text { (Organizaciones } \\
\text { sin personalidad } \\
\text { jurídica que } \\
\text { atienden } \\
\text { hogares) }\end{array}$ & $\begin{array}{l}\text { Centros de padres y apoderados } \\
\text { Centros de alumnos y federaciones } \\
\text { estudiantiles }\end{array}$ & $\begin{array}{l}\text { Estudio del Sector sin Fines de } \\
\text { Lucro en Chile (Irarrázaval et } \\
\text { al., 2006); Mapa de } \\
\text { Organizaciones de la Sociedad } \\
\text { Civil (PUC, 2016) }\end{array}$ \\
\hline 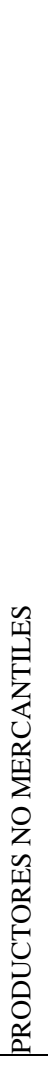 & $\begin{array}{l}\text { Instituciones } \\
\text { privadas sin } \\
\text { fines de lucro } \\
\text { que atienden } \\
\text { hogares }\end{array}$ & 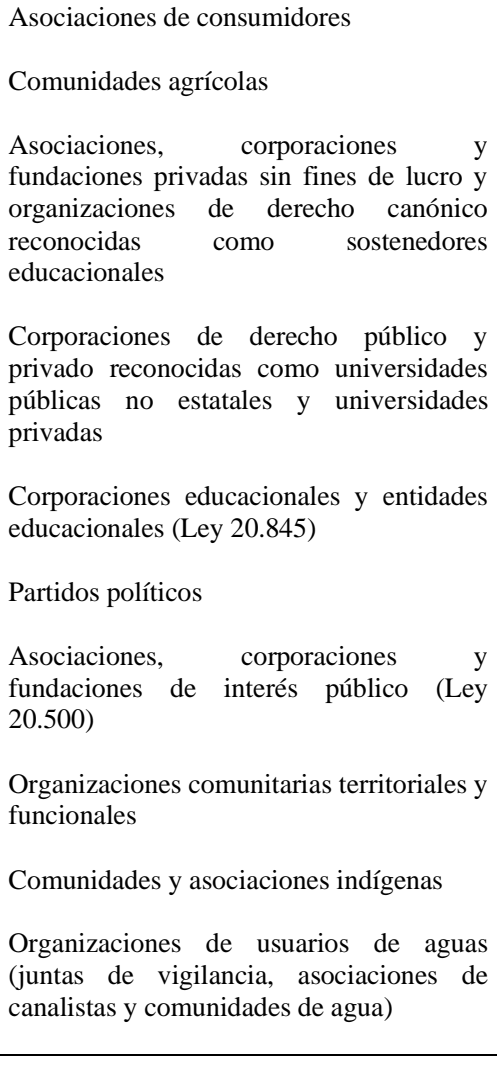 & $\begin{array}{l}\text { Estudio del Sector sin Fines de } \\
\text { Lucro en Chile (Irarrázaval et } \\
\text { al., 2006); Mapa de } \\
\text { Organizaciones de la Sociedad } \\
\text { Civil (PUC, 2016) }\end{array}$ \\
\hline
\end{tabular}




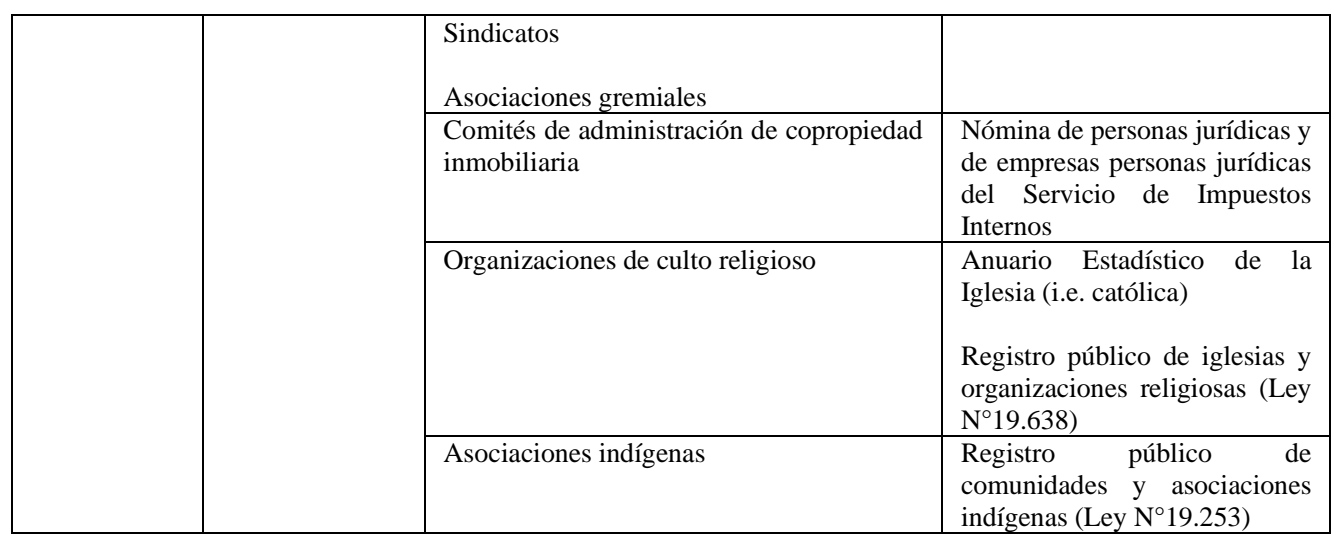

Fuente: Elaboración propia.

\subsection{Dimensionamiento del sector de la economía social}

Para dimensionar el sector de la economía social en términos de algunos indicadores básicos que permitan su comparabilidad internacional, se utilizó la información de ingresos anuales y de trabajadores dependientes informados por la Nómina de Personas Jurídicas y Empresas Personas, publicada por Servicio de Impuestos Internos (2018) para los años tributarios 2006 y 2016, que correspondieron a los ejercicios contables de los años 2005 y 2015, respectivamente $\left({ }^{11}\right)$. Si bien esta nómina identifica a los contribuyentes como organizaciones sin fines de lucro, sobre la base de autorreporte, una revisión exhaustiva de la misma permitió reconoce diversos errores de clasificación. Debido a esto, se diseñó una estrategia de clasificación de la base de datos basada en la razón social o nombre legal de cada contribuyente ${ }^{12}$. Por otra parte, debido a disposiciones legales sobre privacidad de información, los ingresos anuales ${ }^{13}$ de cada persona jurídica o empresa persona contribuyente no fueron reportadas explícitamente sino por tramo. Es decir, cada contribuyente fue clasificado en alguno de los trece tramos de ingresos definidos por el Servicio de Impuestos Internos. Por consiguiente, para determinar el nivel de ingresos se hizo una estimación por tramo basada en la sumatoria del producto resultante de la multiplicación del número de empresas por el valor promedio de ingresos del respectivo tramo. El supuesto implícito en tal estimación es que para muestras grandes el valor esperado promedio de ingresos de cada tramo debería tener una

11 La Nómina de Personas Jurídicas y Empresas Personas considera tanto a entidades personas jurídicas como a personas naturales que actúan como empresas unipersonales. Lamentablemente, la Nómina de Personas Jurídicas y Empresas Personas correspondiente al año tributario 2005 y ejercicio contable 2004, no estuvo públicamente disponible para este estudio.

12 Por ejemplo, para identificar cooperativas se buscaron los nombres o razones sociales de empresas que contenían la expresión "coop" y luego se descartaban aquellas cuyo nombre o razón social evidenciaba que correspondían a otro tipo de entidades.

13 Los ingresos anuales son calculados a través de un algoritmo que integra diversas partidas de la Declaración Anual de Renta y comprende tanto facturación de ventas como ingresos de honorarios por servicios profesionales. 
distribución estadística normal $\left({ }^{14}\right)$. Tal procedimiento debió ser modificado para el último tramo de ingresos, dado que establecía un valor inferior pero no una cota superior de ingresos $\mathrm{y}$, por tanto, no era posible estimar un valor promedio de ingresos para el tramo. Dado que se trataba de un grupo limitado de casos, se procedió a levantar información de ingresos operacionales de cada organización perteneciente a este tramo a partir de estados financieros, memorias y reportes disponibles públicamente. Por su parte, el número de trabajadores dependientes informados en la Nómina de Personas Jurídicas y Empresas Personas fue convertido en jornadas completas equivalentes, utilizando el coeficiente reportado en el estudio de PUC (2017) para el concepto nacional de organización de la sociedad civil. De este modo, fue posible asegurar la comparabilidad de las distintas fuentes de información.

Cabe destacar aquí que si bien los estudios realizados por Irarrázaval et al. (2006) y PUC (2017) para el subsector no mercantil de la economía social realizan una estimación del número de jornadas completas equivalentes de trabajo no remunerado de tipo voluntario, tal estimación no estuvo disponible para el subsector mercantil de la economía social. De este modo se omitió la estimación de esta variable como parte del dimensionamiento del sector de la economía social, cuestión sobre la cual se volverá en el apartado de discusión de resultados.

Finalmente, en el caso de las universidades privadas excluidas del estudio del año 2004, los ingresos operacionales y el número trabajadores remunerados fueron obtenidos de las Fichas Estadísticas de Educación Superior informadas por el Ministerio de Educación. La conversión de número de trabajadores dependientes a jornadas completas equivalentes se hizo a partir del coeficiente reportado en el estudio de PUC (2017) para el concepto nacional de organización de la sociedad civil.

\section{Resultados}

En la Tabla 2 se presenta el número de organizaciones de economía social en Chile formales ${ }^{15}$ para los años 2004 y 2015 y el número de organizaciones que declaraban renta ante el Servicio de Impuestos Internos (SII) de Chile para los años 2005 y 2015. Puede observarse que el crecimiento del número de organizaciones formales es de 114,4 por ciento en este período. Este crecimiento se explica en gran parte por el incremento de las organizaciones comunitarias funcionales y territoriales, cuestión que estaría asociada a la implementación de la Ley №20.500 sobre participación ciudadana y que simplificó el trámite de conformación y adicionalmente consolidó las bases de datos a nivel del Servicio de Registro Civil e Identificación (PUC, 2016). En el caso de las asociaciones indígenas, la información del catastro no estuvo disponible públicamente para el año 2004. Mientras que, en el caso de la copropiedad inmobiliaria, no existe un catastro nacional sino solamente el registro ante el Servicio de Impuestos Internos. Por otra

14 Este supuesto se basa en el Teorema del Limite Central.

15 Es decir, que cuentan con personalidad jurídica vigente o que no tienen personalidad jurídica vigente, pero cuentan con un estatuto y algún directorio público y fidedigno que permite identificarlas, tal como reportaron los estudios de Irarrázaval et al. (2006) y PUC (2016). 
parte, el número de organizaciones que declaran anualmente impuestos ante el Servicio de Impuestos Internos crece en 24,2 por ciento. De modo que al año 2015 sólo un 3,9 por ciento de las organizaciones o empresas que conforman la economía social realizaba declaración anual de impuestos, incluyendo a las que declaraban sin movimiento. Esto podría ser comprensible a la luz de la naturaleza no mercantil de gran parte de las entidades. Sin embargo, llama la atención que sólo un 22,5 por ciento de las cooperativas con personalidad jurídica vigente declaraba impuestos en el año 2015. Esto podría ser indicativo de un gran volumen de actividad económica informal o bien, de carácter no mercantil.

Tabla. 2. Número de organizaciones de economía social de Chile

\begin{tabular}{|c|c|c|c|c|c|}
\hline \multirow{2}{*}{$\begin{array}{l}\text { Figura legal } \\
\text { Año }\end{array}$} & \multicolumn{2}{|c|}{$\begin{array}{l}\text { Personalidad jurídica } \\
\text { vigente }\end{array}$} & \multicolumn{2}{|c|}{$\begin{array}{ll}\begin{array}{l}\text { Declaran } \\
\text { ante el SII }\end{array} & \text { renta } \\
\end{array}$} & \multirow{2}{*}{$\begin{array}{l}\% \\
\text { Declara } \\
2015\end{array}$} \\
\hline & 2004 & 2015 & 2005 & 2015 & \\
\hline Cooperativas & 2.131 & 2.578 & 541 & 579 & 22,5 \\
\hline $\begin{array}{l}\text { Sociedades comerciales constituidas por entidades de } \\
\text { economía social }\end{array}$ & - & - & 28 & 20 & - \\
\hline $\begin{array}{l}\text { Colegios constituidos como sociedades comerciales por } \\
\text { organizaciones religiosas }\end{array}$ & - & - & 251 & 206 & - \\
\hline Organizaciones de la sociedad civil & 106.915 & 234.502 & 4.941 & 6.292 & 2,7 \\
\hline $\begin{array}{l}\text { Organizaciones comunitarias funcionales y territoriales y } \\
\text { sus uniones comunales }\end{array}$ & 56.665 & 182.757 & 2.428 & 2.926 & 1,6 \\
\hline Asociaciones gremiales y sindicatos & 25.660 & 20.612 & 862 & 972 & 4,7 \\
\hline Organizaciones de usuarios de agua y com agrícolas & 1.069 & 3.435 & 133 & 136 & 4,0 \\
\hline $\begin{array}{l}\text { Fundaciones y asociaciones no acogidas a leyes especiales } \\
\text { ong }\end{array}$ & 13.899 & 15.573 & 1.426 & 2.165 & 13,9 \\
\hline Otras & 9.622 & 12.125 & 92 & 93 & 0,8 \\
\hline Asociaciones indígenas & - & 2.074 & 60 & 29 & 1,4 \\
\hline Organizaciones de culto religioso & 6.429 & 8.405 & 317 & 384 & 4,6 \\
\hline Copropiedad Inmobiliaria & - & - & 1.779 & 2.164 & - \\
\hline TOTAL & 115.475 & 247.559 & 7.917 & 9.674 & 3,9 \\
\hline
\end{tabular}

Fuente: Elaboración propia.

Al respecto, la Tabla 3 se presenta una estimación del número de empresas, trabajadores dependientes e ingresos anuales del sector de economía social en Chile para los años 2005 y 2015, según subsector mercantil y no mercantil y figura legal. Cabe destacar que, si bien el número de trabajadores e ingresos anuales reportados corresponden solamente a las organizaciones o empresas que declaran renta ante el Servicio de Impuestos Internos, estimaciones realizadas para el subsector no mercantil de la economía social indican que el reducido grupo de organizaciones o empresas declarantes representaban un 64 por ciento del total de los ingresos ${ }^{16}$ y un 83 por ciento del empleo total del subsector no mercantil

16 Debe destacarse que, siguiendo las recomendaciones para la elaboración de cuentas satélites, los estudios de Irarrázaval et al. (2006) y PUC (2017) reportan una estimación de los gastos y no de los ingresos de las 
estimado a través de una muestra representativa expandida al universo del subsector mercantil (Irarrázaval et al., 2006). Cuestión que se explicaría por la alta concentración de ingresos y empleos remunerados en un reducido grupo de organizaciones.

Tabla. 3. Número de empresas, trabajadores dependientes e ingresos anuales del sector de la economía social en Chile

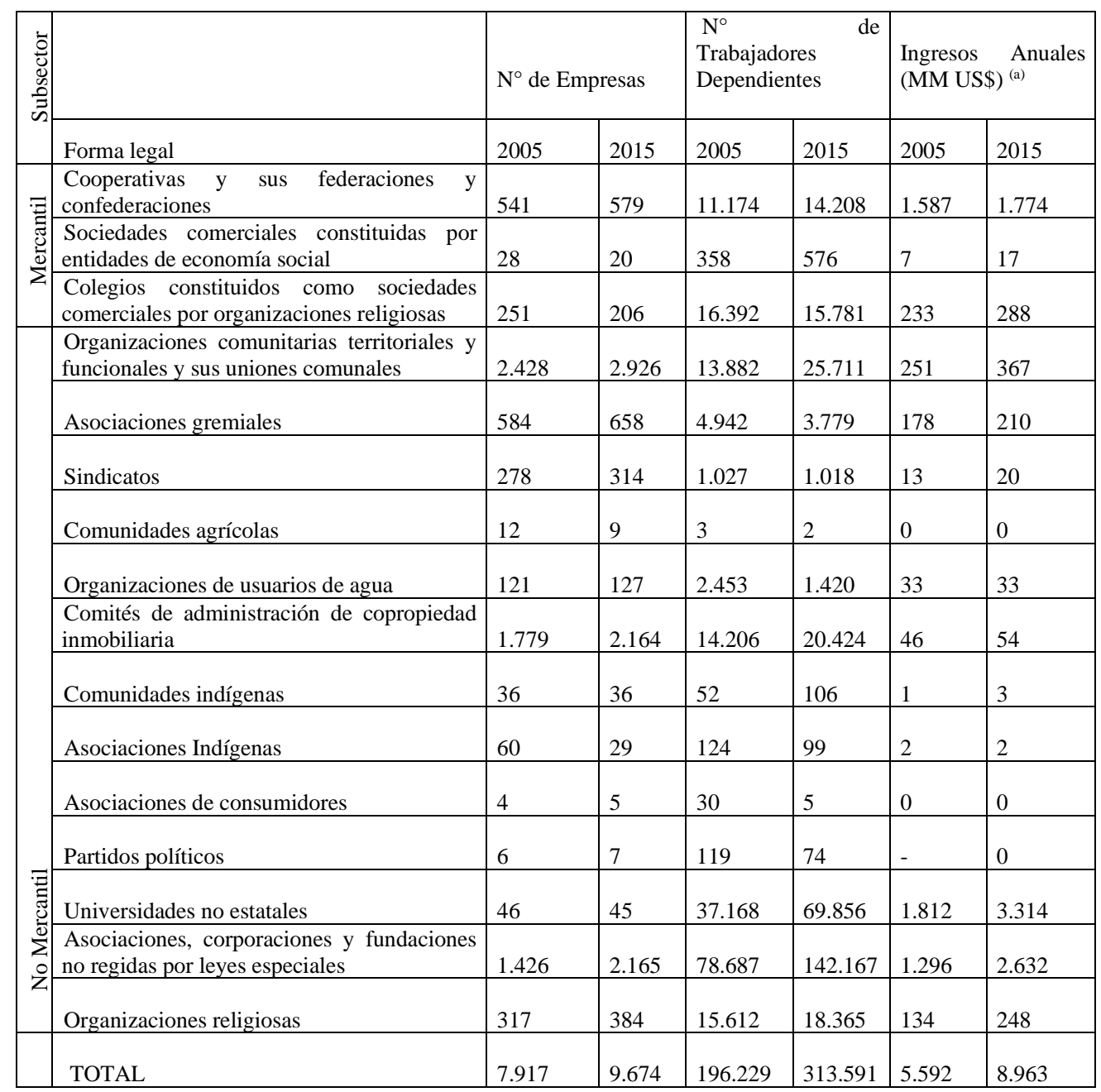

(a) Dólares del año 2015

Fuente: Elaboración propia.

organizaciones de la sociedad civil. La información sobre ingresos sólo está consignada en el apartado metodológico del primero de estos estudios. Sin perjuicio de esto, la información sobre gastos no es reportada por el Servicio de Impuestos Internos y debido a cuestiones de tipo contable y tributario, resultaría menos fidedigna que la información sobre ingresos. 
De acuerdo a esta evidencia es posible suponer también que, pese a la subdeclaración, las estadísticas del Servicio de Impuestos Internos estarían recogiendo prácticamente la totalidad del flujo de ingresos y empleo del sector mercantil de la economía social en Chile.

A partir de estas consideraciones, de la Tabla 3 se tiene que entre 2005 y 2015 los trabajadores dependientes habrían aumentado en 59,8\% y los ingresos habrían crecido en 60,2\%, alcanzado a 313.591 jornadas equivalentes completas y US\$8.963 millones en dólares del año 2015. Desde el punto de vista del empleo, destacan las universidades no estatales, conformadas como corporaciones privadas sin fines de lucro, y las asociaciones, corporaciones y fundaciones no regidas por leyes especiales, muchas de las cuales actúan como administradores o "sostenedores" de establecimientos educacionales de nivel preescolar, básico y medio o bien de servicios de salud o asistencia social. En cuanto a los ingresos, se pueden distinguir claramente los segmentos conformados por cooperativas, universidades no estatales y asociaciones, corporaciones y fundaciones. Finalmente, de la Tabla 3 destaca el hecho que el subsector mercantil representa un 9,7 por ciento del empleo remunerado y el 23,2 por ciento de los ingresos de la economía social en Chile.

Corroborando los hallazgos anteriores, la Tabla 4 presenta el número de empresas e ingresos anuales del sector de la economía social en Chile según tamaño, utilizando la clasificación del Servicio de Impuestos Internos para los distintos tramos.

Tabla. 4. Número de empresas e ingresos anuales según tramo de ingresos

\begin{tabular}{|c|c|c|c|c|c|c|}
\hline \multirow[b]{2}{*}{ Tramo de ingresos } & \multicolumn{3}{|c|}{$\mathrm{N}^{\circ}$ de Empresas } & \multicolumn{3}{|c|}{ Ingresos Anuales (MM US\$) (a) } \\
\hline & 2005 & 2015 & $\begin{array}{l}\% \\
\text { Variación }\end{array}$ & 2005 & 2015 & $\begin{array}{l}\% \\
\text { Variación }\end{array}$ \\
\hline No informa ingresos & 3.681 & 4.396 & 16,3 & - & - & - \\
\hline Micro (Desde US\$1 a US\$7.280) & 2.875 & 3.286 & 12,5 & 67 & 88 & 23,8 \\
\hline $\begin{array}{l}\text { Pequeña (Desde } \text { US\$7.281 a } \\
\text { US\$910.120) }\end{array}$ & 891 & 1.274 & 30,1 & 308 & 420 & 26,8 \\
\hline $\begin{array}{l}\text { Mediana (Desde US\$910.121 a } \\
\text { US\$3.640.483) }\end{array}$ & 304 & 464 & 34,5 & 804 & 1.286 & 37,5 \\
\hline $\begin{array}{l}\text { Grande (Desde US\$3.640.484 a } \\
\text { US\$36.404.830 }\end{array}$ & 142 & 215 & 34,0 & 1.578 & 2.257 & 30,1 \\
\hline $\begin{array}{l}\text { Super Grande (US\$36.404.831 y } \\
\text { más) }\end{array}$ & 24 & 39 & 38,5 & 2.835 & 4.911 & 42,3 \\
\hline Total & 7.917 & 9.674 & 18,2 & 5.592 & 8.963 & 37,6 \\
\hline
\end{tabular}

(a) Dólares del año 2015

Fuente: Elaboración propia.

Puede observarse que al año 2015 un 0,4 por ciento del total de empresas u organizaciones concentraban un 54,8 por ciento de los ingresos del sector de la economía social. Adicionalmente, si bien se verifica un crecimiento del ingreso en 
todos los segmentos, en los tramos que corresponden a micro y pequeña empresa el crecimiento es inferior. Finalmente, destaca un 45,4 por ciento de las empresas que el año 2015 declararon no recibir ingreso alguno.

La Tabla 5 muestra los ingresos anuales del sector de la economía social según sector de la actividad económica.

Tabla. 5. Ingresos anuales del sector de la economía social según sector de la actividad económica

\begin{tabular}{|c|c|c|c|}
\hline \multirow[b]{2}{*}{ Sector de actividad económica } & \multicolumn{3}{|c|}{ Ingresos (MM US\$) } \\
\hline & 2005 & 2015 & Var. \% \\
\hline Agricultura, ganadería, caza y silvicultura & 108 & 149 & 27,5 \\
\hline Pesca & 18 & 21 & 15,1 \\
\hline Explotación de minas y canteras & 0 & 0 & 17,9 \\
\hline Industrias manufactureras no metálicas & 1.032 & 903 & $-14,3$ \\
\hline Industrias manufactureras metálicas & 7 & 17 & 61,3 \\
\hline Suministro de electricidad, gas y agua & 108 & 188 & 42,7 \\
\hline Construcción & 5 & 12 & 58,3 \\
\hline $\begin{array}{l}\text { Comercio al por mayor y menor, reparación de vehículos, } \\
\text { automotores y enseres domésticos }\end{array}$ & 450 & 902 & 50,1 \\
\hline Hoteles y restaurantes & 30 & 93 & 67,5 \\
\hline Transporte, almacenamiento y comunicaciones & 75 & 34 & $-116,3$ \\
\hline Intermediación financiera & 186 & 481 & 61,2 \\
\hline Actividades inmobiliarias, empresariales y de alquiler & 252 & 512 & 50,8 \\
\hline $\begin{array}{l}\text { Administración pública y defensa, planes de Seguridad Social de } \\
\text { afiliación obligatoria }\end{array}$ & - & - & - \\
\hline Enseñanza & 2.634 & 4.719 & 44,2 \\
\hline Servicios sociales y de salud & 174 & 310 & 43,8 \\
\hline Otras actividades de servicios, comunitarias, sociales y personales & 443 & 619 & 28,4 \\
\hline Consejos de administración de edificios y condominios & 0 & 1 & 79,5 \\
\hline Organizaciones y órganos extraterritoriales & 5 & 0 & - \\
\hline Sin información & 63 & - & - \\
\hline TOTAL & 5.592 & 8.963 & 37,6 \\
\hline
\end{tabular}

(a) Dólares del año 2015

Fuente: Elaboración propia. 
Puede observarse la importante concentración de los ingresos en el sector de enseñanza, que al año 2015 representaba un 52,6 por ciento de ellos. Le siguen en importancia el sector de industrias manufactureras no metálicas, representado principalmente por Cooperativa Agrícola y Lechera La Unión (COLUN) y el sector de comercio, representado por cooperativas dedicadas a la comercialización de insumos agropecuarios en lo principal.

En cuanto al crecimiento, mientras las actividades primarias muestran una expansión por debajo del promedio, varias actividades secundarias y terciarias crecen fuertemente en ingresos. Por su gravitación económica destacan la construcción, la intermediación financiera, los servicios sociales y de salud y las actividades inmobiliarias, empresariales y de alquiler, todos los cuales aparecen siguiendo el ritmo de crecimiento a nivel nacional de estas actividades en Chile (OECD, 2018).

\section{Discusión}

Para dar cuenta de la calidad de la metodología empleada para dimensionar el sector de la economía social en Chile, en la Tabla 6 se presentan sintéticamente los resultados reportados por estudios focalizados en el subsector no mercantil de la economía social, bajo la denominación de instituciones sin fines de lucro $\mathrm{u}$ organizaciones de la sociedad civil (Irarrázaval et al., 2006; PUC, 2016). Estos resultados fueron obtenidos aplicando una encuesta a una muestra representativa de un catastro nacional de organizaciones y posteriormente expandiendo los datos al universo considerado Cabe destacar que tanto el número de organizaciones, trabajadores remunerados y gastos del año 2004 han sido ajustados para incluir a las universidades no estatales que originalmente fueron omitidas de ambos estudios.

Tabla. 6. Caracterización del subsector no mercantil de la economía social según muestra expandida

\begin{tabular}{|l|c|c|c|}
\hline Indicador & 2004 & 2015 & Var \% \\
\hline $\mathrm{N}^{\circ}$ de organizaciones de la sociedad civil & 106.880 & 234.502 & 119,4 \\
\hline $\mathrm{N}^{\circ}$ de trabajadores remunerados (JCE) & 160.259 & 145.254 & $-9,4$ \\
\hline $\mathrm{N}^{\circ}$ de voluntarios (JCE) & 143.624 & 164.865 & 14,8 \\
\hline Gastos (MM US\$) (a) & 3.446 & 5.028 & 45,9 \\
\hline
\end{tabular}

(a) Dólares del año 2015

Fuente: Elaboración propia.

En la Tabla 7 se presentan los resultados obtenidos utilizando la base de datos de Nómina de Personas Jurídicas y Empresas Personas, reportada por Servicio de Impuestos Internos (2018), para el mismo tipo de organizaciones del subsector no mercantil consideradas en los estudios sobre las organizaciones de la sociedad civil en Chile (PUC, 2017). 
Tabla. 7. Caracterización del subsector no mercantil de la economía social según Nómina de Personas Jurídicas y Empresas Personas del Servicio de Impuestos Internos

\begin{tabular}{|l|r|r|r|}
\hline Indicador & 2005 & 2015 & Var \% \\
\hline $\mathrm{N}^{\circ}$ de organizaciones de la sociedad civil & 4.941 & 6.292 & 27,3 \\
\hline $\mathrm{N}^{\circ}$ de trabajadores dependientes & 138.363 & 244.138 & 76,4 \\
\hline Ingresos (MM US\$ 2015) $^{\text {(a) }}$ & 3.584 & 6.580 & 83,6 \\
\hline
\end{tabular}

(a) Dólares del año 2015

Fuente: Elaboración propia.

Comparando ambas tablas y estrategias de estimación se puede observar que aun cuando el concepto de trabajador remunerado medido en jornadas completas equivalentes (JCE) no es perfectamente homologable al de trabajador dependiente, los datos del Servicio de Impuestos Internos recogen una parte importante de lo reportado por la muestra expandida entre 2004 y 2005 . Una brecha mayor se observa en la comparación del año 2015. Por otra parte, al comparar la trayectoria de los gastos estimados a través de encuestas con los ingresos, estimados a través de las Declaración Anual de Renta del Servicio de Impuestos Internos, observamos una importante similitud entre 2004 y 2005 y nuevamente diferencias mayores en el año 2015. De este modo puede decirse que debido a la concentración de los ingresos y del empleo en un grupo reducido de organizaciones o empresas del sector de la economía social, los antecedentes del Servicio de Impuestos Internos recogen una parte significativa de la información y capturan las tendencias del sector de la economía social en Chile en lo referido a ingresos y empleo dependiente o remunerado. No se puede decir lo mismo en relación al trabajo voluntario o no remunerado, que solamente ha sido estimado por Irarrázaval et al. (2006) y PUC (2017) sobre la base de una muestra representativa de parte del subsector mercantil, expandida al universo analizado. En este sentido, en la Tabla 6 puede observarse que al menos la mitad de las jornadas completas equivalentes laboradas en la economía social corresponden a trabajo voluntario y posiblemente está relacionada con bienes y servicios de tipo no mercantil que resultan invisibles para el Servicio de Impuestos Internos.

Por otra parte, al comparar las bases de datos que informan de la existencia formal de empresas u organizaciones que pueden reconocerse como el sector de la economía social, con aquellas registradas ante la autoridad tributaria puede observarse un importante subregistro como fue indicado precedentemente. En efecto, de acuerdo al Servicio de Impuestos Internos, a agosto del 2017 existían en Chile unas 278.000 organizaciones sin fines de lucro de las cuales sólo 40.263 habían iniciado actividades para efectos tributarios (La Tercera, 2018). De este universo, 29.649 debían haber declarado Impuesto a la Renta, pero solamente 7.697 lo hicieron ${ }^{17}$.

17 Esta estimación es consistente con el estudio de PUC (2016) que determinó un universo de 235.000 organizaciones de la sociedad civil formalmente existentes en Chile, considerando aquí la exclusión de diversas expresiones no mercantiles y de la totalidad del subsector mercantil. 
A partir de los antecedentes obtenidos y asumiendo estos sesgos de subdeclaración identificados, es posible determinar la relevancia de la economía social en Chile desde el punto de vista de los ingresos y del empleo, comparándola con el Producto Interno Bruto y con la población ocupada de $\mathrm{Chile}^{18}$, respectivamente. La Tabla 8 presenta esta información.

Tabla. 8. Participación del sector de la economía social de Chile en la PEA y PIB

\begin{tabular}{|l|l|l|}
\hline Año & 2005 & 2015 \\
\hline $\mathrm{N}^{\circ}$ de trabajadores dependientes / $\mathrm{N}^{\circ}$ de ocupados país & 3,1 & 3,8 \\
\hline Ingresos / PIB & 4,4 & 3,7 \\
\hline
\end{tabular}

Fuente: Elaboración propia.

De esto se desprende que el sector de la economía social ha reducido su participación en el PIB entre 2005 y 2015 pero ha incrementado su relevancia en el empleo, en idéntico período. Por otra parte, de acuerdo al indicador de empleo pagado como porcentaje del empleo total, la economía social en Chile sería menor que la de Portugal y superior a la de Grecia y Polonia, países de ingreso per cápita similares al de Chile (ESSC/CIRIEC, 2016).

Finalmente, en el proceso de dimensionar y caracterizar el sector de la economía social sobre la base de consideraciones formales fue posible establecer diversas problemáticas que apuntan hacia la necesidad de ampliar y complementar este enfoque y que tienen que ver con la brecha entre las definiciones formales y la realidad sustantiva de la economía social. En particular, en el caso de las asociaciones gremiales ${ }^{19}$ se cuentan no sólo aquellas que articulan a la pequeña producción mercantil (por ej. agricultura familiar campesina, artesanado, pesca artesanal, etc.) o a determinados oficios (por ej. taxistas, transportistas, feriantes, etc.) sino también a gremios de las principales empresas de capital de Chile, como la Sociedad de Fomento Fabril o la Cámara Chilena de la Construcción, considerado entre los 20 principales grupos económicos de Chile desde el punto de vista de capitalización (CEEN, 2017). En el caso de corporaciones y fundaciones, destaca el segmento que corresponde a universidades privadas y a administradores de establecimientos educacionales que reciben aportes estatales para su funcionamiento y que han sido parte de un extenso debate público sobre el lucro en la educación (Guzmán et al., 2014; Kremerman, 2007). Específicamente, se cuentan diversos casos de sociedades lucrativas que invierten en infraestructuras educacionales y luego pasan a integrar corporaciones o fundaciones privadas sin fines de lucro que conforman universidades y a las cuales les arriendan estas infraestructuras. Por su parte, en las redes de Comercio Justo encontramos entidades conformadas como sociedades comerciales y que no necesariamente son controladas por entidades de la economía social. Este es el caso de sociedades

18 Se considera el trimestre móvil octubre-diciembre de cada año, reportado por el Instituto Nacional de Estadísticas.

19 Conformadas con arreglo a la Ley N².757 de 1979. 
limitadas, sociedades anónimas cerradas y sociedades por acciones, conformadas por pequeños productores agrícolas. Del mismo modo, la copropiedad inmobiliaria presenta una diversidad de casuística, que va desde una asamblea de copropietarios que mandata a un administrador privado, sea persona natural o jurídica, para velar por la mantención de los bienes comunes, hasta la propia conformación de los copropietarios como organización comunitaria, sociedad anónima cerrada o sociedad limitada.

Durante la ejecución del estudio se hizo evidente que, en distintos casos, entidades jurídicamente reconocibles como parte de la economía social conformaron sociedades mercantiles con el fin de operar en el marco de políticas públicas o privadas que sólo admitían este tipo de figuras legales. A modo de ejemplo, en el caso de las subvenciones de capacitación laboral financiadas por el Servicio Nacional de Capacitación y Empleo (SENCE), dependiente del Ministerio del Trabajo y Previsión Social, las entidades beneficiarias deben tener como objeto social único la capacitación. Lo que lleva a distintas corporaciones, fundaciones o asociaciones a conformar una filial privada para fines de utilizar la subvención. En el caso del acceso a financiamiento, una política extendida de la banca privada es no prestar a entidades sin fines de lucro, aún si cuentan con flujos económicos y patrimonio o avales significativos que caucionen sus compromisos. Esto se origina tanto en el hecho que las normas de clasificación de riesgo obligan a las entidades bancarias a provisionar garantías con su propio capital como al hecho que el procedimiento concursal de liquidación regido por la Ley 20.720, está diseñado para sociedades mercantiles. En menor medida, también se plantea el riesgo reputacional que le significa a una entidad financiera privada solicitar la liquidación de una entidad sin fines de lucro que realiza labores de asistencia social, en el caso de incumplimiento de obligaciones.

Finalmente, una mención especial merece el tratamiento de la microempresa familiar en el dimensionamiento y caracterización del sector de la economía social, realidad que jurídicamente es reconocida a través de la Ley 19.749. De acuerdo a la Nómina de Contribuyentes reportada por Servicio de Impuestos Internos (2018), al año 2015 en Chile existían unas 609 mil empresas que cuentan con un solo trabajador dependiente, considerando tanto aquellas que corresponden a personas naturales como aquellas que corresponden a sociedades mercantiles. Esto representaba el 57 por ciento del total de empresas que declaraban impuestos en el país. Por su parte, de acuerdo a las estadísticas de la Encuesta Nacional del Empleo del Instituto Nacional de Estadísticas, en el mismo año un millón de personas declaraba trabajar informalmente por cuenta propia, por lo cual la microempresa familiar podía representar a más de 1,6 millones de empresas en Chile.

Este conjunto de empresas o emprendimientos suelen cumplir con gran parte de los criterios que podrían definirlos como parte de la economía social, partiendo por la relación de comensalidad y reciprocidad que fundan el vínculo familiar o los fines de ayuda mutua que persiguen estas unidades. No obstante, se da la paradoja de que, al seguir los criterios formales de clasificación de empresas, una sociedad mercantil conformada por una, dos o tres trabajadores vinculados familiarmente no sería considerada parte de la economía social pero una asociación gremial o una corporación privada sin fines de lucro conformadas por empresas de capital, sería considerada parte de la economía social. En este sentido, la distinción propuesta 
por Coraggio et al. (2010) entre economía solidaria y economía popular solidaria tendría pleno sentido para la realidad chilena y latinoamericana, permitiendo distinguir entre tipos de racionalidades presentes al momento de conformar asociaciones.

\section{Conclusiones}

A partir de la revisión de estudios y registros públicos de empresas y organizaciones de la sociedad civil, ha sido posible dimensionar y caracterizar preliminarmente el sector de la economía social en Chile. Al año 2015 este sector estaba conformado por unas 247.559 organizaciones o empresas formales, siendo gravitante el sector no mercantil conformado por organizaciones comunitarias y por asociaciones, corporaciones o fundaciones privadas sin fines de lucro. De acuerdo a los registros disponibles a nivel del Servicio de Impuestos Internos, la economía social en Chile emplearía a 313.591 trabajadores dependientes y generaría ingresos monetarios por US\$8.963 millones. Estas cifras serían equivalentes al 3,8 por ciento de la ocupación y del 3,7 por ciento del PIB de Chile, respectivamente, situando al país por debajo del promedio de la Unión Europea y por encima de países de ingreso per cápita comparables como Grecia o Polonia. No obstante, debido a la alta tasa de organizaciones y empresas informales estos valores estarían subestimados en un rango de 64 a 83 por ciento, respectivamente. Más aún, antecedentes relativos al empleo voluntario o no remunerado en el subsector no mercantil, indicarían hacia la duplicación en el número de trabajadores y que hoy resultan invisibles para las estadísticas utilizadas del Servicio de Impuestos Internos.

La economía social en Chile aparece fuertemente vinculada al sector educacional, debido al peso económico de diversas entidades que ejercen como administradores de establecimientos de enseñanza preescolar, básica y media y también de universidades no estatales conformadas como corporaciones privadas sin fines de lucro. En efecto, casi un 54 por ciento de los ingresos de la economía social son aportados por este sector de la actividad económica. Esto mismo explica una alta concentración económica, donde el 0,4 por ciento de las entidades reciben el 54,8 por ciento de los ingresos generados por el sector. Considerando el debate público sobre el lucro encubierto con las subvenciones públicas en el sector educacional, estos antecedentes apuntan hacia un principal tema de interés para el desarrollo de la economía social en Chile.

En el período 2005-2015 sector de la economía social presenta un importante dinamismo desde el punto de vista de creación de empresas u organizaciones, contratación de trabajadores dependientes y generación de ingresos. No obstante, mientras su participación en la ocupación nacional crece de 2,9 por ciento a 3,8 por ciento, la participación en el Producto Interno Bruto cae de 4,4 por ciento a 3,7 por ciento. Desde el punto de vista de sectores de actividad económica, el crecimiento de la economía social tiende a ser mayor en aquellas actividades económicas más dinámicas a nivel nacional, lo que no permite caracterizarla como un sector/espacio "colchón" de la situación de los otros sectores de la economía. 
Finalmente, de la revisión del conjunto de antecedentes levantados para el presente estudio puede deducirse una importante brecha entre los criterios formales de clasificación de las entidades de economía social y la realidad sustantiva de su funcionamiento. Esto lleva a la necesidad no sólo de mejorar los sistemas de registro sino fundamentalmente a discutir criterios complementarios que permitan una delimitación más adaptada a la realidad chilena y latinoamericana (Fajardo García, 2018).

\section{Referencias bibliográficas}

Alcalde, J. (2015) Notas sobre el concepto de persona jurídica sin fines de lucro a propósito de la Ley 20.845 sobre inclusión escolar. Revista Chilena de Derecho Privado, $\mathrm{N}^{\circ} 25$. Disponible en: http://dx.doi.org/10.4067/S0718-80722015000200016.

Alcalde, J. (2016) Actualidad legislativa. Observaciones al proyecto de ley que regula las empresas sociales. Revista Chilena de Derecho Privado, $\mathrm{N}^{\circ} 26$. Disponible en: http://dx.doi.org/10.4067/S0718-80722016000100014.

Bajoit, G. y Vanhulst, J. (2016) Las acciones colectivas conflictivas: el caso del movimiento estudiantil chileno. Anuari del conflicte social, $\mathrm{N}^{\circ} 6$, pp. 21-60.

Boltanski, L. \& Chiapello, E. (1999) Le nouvel esprit du capitalisme. Paris: Gallimard. 980 p.

Bourdieu, P. (2000) La dominación masculina. Barcelona: Editorial Anagrama. 159 p.

Brand, U. (2015) Degrowth und Post-Extraktivismus: Zwei Seiten einer Medaille? Working Paper, Nr. 5, Jena: DFG-KollegforscherInnengruppe Postwachstumsgesellschaften. 43 p.

CEEN (2017) Ranking de grupos económicos RGE 2017. Santiago de Chile: Universidad del Desarrollo. Disponible en: http://ceen.udd.cl/files/2018/10/RGE-17-12vf.pdf.

Chaves Ávila, R., Monzón Campos, J., Pérez de Uralde, J. y Radrigán, M. (2013) La economía social en clave internacional. Cuantificación, reconocimiento institucional y visibilidad social en Europa, Iberoamérica y Norte de África. REVESCO. Revista de Estudios Cooperativos, $\mathrm{N}^{\circ} 112$, pp. 122-150. DOI:

https://doi.org/10.5209/rev_REVE.2013.v112.43069.

Concertación de Partidos por la Democracia (1989) Programa de Gobierno: Patricio Aylwin. Santiago de Chile: Jurídicas Publiley. Disponible en: http://www.memoriachilena.gob.cl/602/w3-article-61814.html

CONFECOOP (2017) Diagnóstico y propuestas para el fortalecimiento de la economía cooperativa, social y solidaria. Santiago de Chile: Confederación General de Cooperativas de Chile. $30 \mathrm{p}$.

Coraggio, J.L. (1994) Del sector informal a la economía popular. Alternativas populares de desarrollo social. Nueva Sociedad, $\mathrm{N}^{\circ} 131$, pp. 118-131.

Coraggio, J. L. (1998) Economía urbana: la perspectiva popular. Quito: Editorial Abya Yala. $182 \mathrm{p}$.

Coraggio, J.L., Arancibia, M.I., y Deux, M.V. (2010) Guía para el mapeo y relevamiento de la economía popular solidaria en Latinoamérica y el Caribe. Lima: GRESP. 88 p.

Costanza, R., Alperovitz, G., Daly, H., Farley, J., Franco, C., Jackson, T.\& Victor, P. (2013) Building a sustainable and desirable economy-in-society-in-nature. In: The worldwatch institute (Ed.), State of the world 2013. Washington, DC: Island Press, pp. $126-142$. 
DAES (2015) Panorama y proyecciones de la economía social y cooperativa en Chile. Santiago de Chile: Ministerio de Economía, Fomento y Turismo. 33 p.

Dardot, P., \& Laval, C. (2009) La nouvelle raison du monde: Essai sur la société néolibérale. Paris: Editions La Découverte. 498 p.

De la Maza, G. (2002) Sociedad civil y democracia en Chile. En: Panfichi, A. (Ed.) Sociedad civil, esfera pública y democratización en América Latina: Andes y Cono Sur. Lima: Universidad Católica del Perú, pp. 211-240.

De Nanteuil, M. \& Laville, J.L., (2014) Crisis of Capitalism and Plural Economy: An Anthropological Perspective. L'Option de Confrontations Europe, $\mathrm{N}^{\circ} 33$, pp. 69-78.

EESC/CIRIEC (2012) The social economy in the European Union. Brussels: European Economic and Social Committee. $116 \mathrm{p}$.

EESC/CIRIEC (2016) Recent evolutions of the social economy in the European Union. Brussels: European Economic and Social Committee. 122 p.

Escobar, A. (1992) Imagining a post-development era? Critical thought, development and social movements. Social text, $\mathrm{N}^{\circ} 31 / 32$, pp. 20-56.

Escobar, A. (1995) Encountering development: the making and unmaking of the third world. New Jersey: Princeton University Press. 290 p.

Escobar, A. (2011) Sustainability: design for the pluriverse. Development, N54, pp. 137140.

Fajardo García, G. (2018) La identificación de las empresas de economía social en España. Problemática jurídica. REVESCO. Revista de Estudios Cooperativos, Segundo Cuatrimestre, $\mathrm{N}^{\circ} 128$, pp. 99-126. DOI: https://doi.org/10.5209/REVE.60209.

Gibson-Graham, J.K. (2006) A Postcapitalist politics. Minneapolis: University of Minnesota Press. 360 p.

Gibson-Graham, J.K., Cameron, J., \& Healy, S. (2013) Take back the economy: an ethical guide for transforming our communities. Minneapolis: University of Minnesota Press. $264 \mathrm{p}$.

Gide, Ch. (1930). Principes d'economie politique (26e Ed.) Paris: Librairie du Recueil Sirey. $682 \mathrm{p}$.

Gonzalez-Meyer, R. y Richards, H. (2012) Hacia otras economías: crítica al paradigma dominante. Santiago de Chile: Universidad Academia de Humanismo Cristiano y Universidad Católica del Maule. 453 p.

Gonzalez-Meyer, R. \& Donovan, P. (2004) Economie social, populaire, et solidaire au Chili (1980-2003). Chaire de recherche du Canada en développement des collectivités (CRDC), Série comparaisons internationales $\mathrm{N}^{\circ} 15$. Quebec: Université du Québec en Outaouais. 24 p.

González-Meyer, R., Vanhulst, J., Letelier, E. Cid, B. y de Armas, T. (2016) Servicio de consultoría para la elaboración de estudio de bases para el diseño de un observatorio del emprendimiento social y de las empresas sociales en Chile: informe final. Santiago de Chile: Universidad Academia de Humanismo Cristiano y Universidad Católica del Maule. 123 p.

González-Meyer, R. (2018) Aportes para una definición plural y en tensión de la economía social y solidaria: entre el esencialismo y el historicismo. Santiago de Chile: Universidad Academia de Humanismo Cristiano.

Gaiger, I. (2017) El sentido metautilitarista de la economía social y solidaria. En: González-Meyer, R. (Ed.). Ensayos sobre economía cooperativa, solidaria y autogestionaria: hacia una economía plural. Santiago de Chile: Editorial Forja, pp. 87105. 
Granovetter, M. (1985) Economic action and social structure: the problem of embeddedness. American Journal of Sociology, Nº1, 481-510.

Guerra, P. (2010) La economía solidaria en Latinoamérica. Papeles de Relaciones Ecosociales y Cambio Global, $\mathrm{N}^{\circ} 110,67-76$.

Guzmán, J.A., González, M., Figueroa, J.P. y Riquelme, G. (2014) La gran estafa: cómo opera el lucro en la educación superior. Santiago de Chile: Editorial Catalonia.

Harvey, D. (2014) Seventeen contradictions and the end of capitalism. Oxford: Oxford University Press.

Healy, S. (2009) Alternative economies. In: Thrift, N. J.; Kitchin, R. (Eds.). International encyclopedia of human geography. Oxford: Elsevier, pp. 338-344.

Irarrázaval, I., Hairel, E., Wojciech Sokolowsky, S. y Salomon, L. (2006) Estudio comparativo del sector sin fines de lucro-Chile. Santiago de Chile: John Hopkins University, PNUD y FOCUS.

Kremerman, M. (2007) Radiografía del financiamiento de la educación chilena: diagnóstico, análisis y propuestas. Santiago de Chile: Observatorio Chileno de Políticas Educativas. 297 p. Disponible en: http://www.opech.cl/Libros/doc3.pdf

La Tercera (2018, 12 de enero) SII alerta que más del 90\% de las entidades sin fines de lucro no tiene registros contables. Disponible en: http://www2.latercera.com/noticia/siialerta-mas-del-90-las-entidades-sin-fines-lucro-no-registros-contables/.

Leff, E. (2014) La apuesta por la vida: imaginación sociológica e imaginarios sociales en los territorios ambientales del sur. Barcelona: Siglo XXI Editores. 524 p.

Mauss, M. (1925) Essai sur le don, forme et raison de l'echange dans le societes archaiques. L’Annee sociologique, $\mathrm{N}^{\circ} 1,7-29$.

Meira, D. (2019) The cooperative economic groups and the problem of the quantification of the social economy entities. REVESCO. Revista de Estudios Cooperativos, Segundo Cuatrimestre, $\mathrm{N}^{\circ} 131$, pp. 103-124. DOI: https://doi.org/10.5209/REVE.63562.

Monzón, J.L. y M. Radrigán (2009) El observatorio iberoamericano del empleo y la economía social (OIBESCOOP) y el fortalecimiento de la economía social. En : Fundibes. Anuario iberoamericano de la economía social 2009. Madrid: Fundibes, pp. 131-138.

OECD (2018) OECD Economic Surveys: Chile. Disponible en: https://www.oecd.org/eco/surveys/Chile-2018-OECD-economic-survey-overview.pdf.

Polanyi, K. (1944) The great transformation: the political and economic origins of our time. Boston: Beacon Press. 360 p.

Pleyers, G. \& Capitaine, B. (Eds.) (2016) Jeunes alteractivistes: d'autres manières de faire de la politique : perspectives internationales. Agora débats / jeunesses, $\mathrm{N}^{\circ} 73$. Paris: Les Presses de Sciences Po, 157 p.

PNUD (2015) Desarrollo humano en Chile: los tiempos de la politización 2015. Santiago de Chile: Programa de Naciones Unidas para el Desarrollo. 263 p.

PUC (2016) Mapa de las organizaciones de la sociedad civil 2015. Santiago de Chile: Pontificia Universidad Católica de Chile. 39 p.

PUC (2017) Sociedad en acción: Construyendo Chile desde las organizaciones de la sociedad civil. Santiago de Chile: Pontificia Universidad Católica de Chile. 208 p.

Radrigán, M. y Barría, C. (2005) Situación y proyecciones de la economía social en Chile. En: Pérez de Uralde, J. M. (Ed.), Panorama de la economía social en Iberoamérica. Un acercamiento a su realidad. Madrid: FUNDIBES, pp.93-138. Disponible en: https://www.aciamericas.coop/IMG/pdf/ESIberoamerica1.pdf

Razeto, L. (1994) Fundamentos de una teoría económica comprensiva. Santiago de Chile: PET Ediciones. 506 p. 
Sahlins, M. (1972) Stone age economics. Chicago: Aldin Atherton. 348 p.

Servicio de Impuestos Internos (2018). Nómina de empresas jurídicas AT 2006-2016. Disponible en: http://www.sii.cl/estadisticas/nominas/empresas_perjurihistorico.zip.

Stoessel, S. (2014) Giro a la izquierda en la América Latina del siglo XXI: revisitando los debates académicos. Polis, $\mathrm{N}^{\circ} 39$, pp.123-149.

Vásquez, L.G. y Juppet, M.F. (2013) Derecho del tercer sector: corporaciones, fundaciones y cooperativas. Santiago de Chile: Thompson Reuters. $230 \mathrm{p}$.

Weber, M. (1922) Economía y sociedad. Ciudad de México: Fondo de Cultura Económica. $1246 \mathrm{p}$. 